\title{
Reforestation of abandoned pasture on Hokkaido, northern Japan: effect of plantations on the recovery of conifer-broadleaved mixed forest
}

\author{
Kikuko Shoyama
}

Published online: 16 April 2008

(C) International Consortium of Landscape and Ecological Engineering and Springer 2008

\section{Erratum to: Landscape Ecol Eng}

\section{DOI 10.1007/s11355-008-0034-7}

The original version of this article unfortunately contained a mistake. The legend to Fig. 4 was incorrect. The corrected legend is given below.

Fig. 4 DCA ordination diagram showing the plot scores. The first and second axes accounted for 34 and $28 \%$ of the total variance, respectively. Vegetation type a, Sasa community, open triangle; type b, meadow community, open square; type A, conifer-broadleaved forest, filled circle; type $\mathrm{B}$, broadleaved forest, filled triangle; type $\mathrm{C}$, birch plantation, filled square; type $\mathrm{D}$, larch plantation, filled diamond; Control, cross + circle; gray years 1986-1988; black years 2005-2006 